\title{
El Profesor Doctor Hernán Alessandri: su legado para las nuevas generaciones de médicos
}

\author{
SEBASTIAN ROSSON M.
}

\section{Professor Hernán Alessandri, M.D.: his legacy for the new generations of physicians}

Professor Alessandri died in 1980. We started our residency in Internal Medicine about 30 years later. Considering the profound changes our society has witnessed, including medical practice, I would like to approach the meaning of his work for our generation. It is not the Father's figure nor his Aura what inspires us today. Neither is his personality nor his shape. His universality comes from his transcendent image as a teacher. Today's teachers live rough times, their social status has changed, their professional requirements have grown exponentially, they have to adapt to social phenomena like the Internet and multiculturalism. Being a teacher nowadays demands to be a multifaceted expert. Things have changed since Professor Alessandri made rounds with his patients. But a deeper look allows us to understand that everything returns to where it started: professional deontology of the teacher, never fading but transcendent. We know that Doctor Alessandri had the natural gift to keep faithful to that code with consistency and perseverance. He excelled with integrity in every aspect including professional betterment, constructive work for his institution, collegiality, a warm relationship with students and a model of social values. Beyond virtues and personal defects he will keep on being the mould in which present teachers should be formed, engraved in their souls and in the subconscious of students that seek to learn.

(Rev Med Chile 2015; 143: 109-111)

Key words: Chile; Education, medical; Famous persons; History of Medicine, 20th Century.

$\mathrm{E}$ 1 Profesor Alessandri falleció en 1980. Yo tenía un año de edad. Los actuales becarios de Medicina Interna pisamos las antiguas baldosas del Hospital del Salvador tres décadas más tarde. Para nosotros el contacto más cercano con el Profesor son su placa recordatoria en la subida al segundo piso, las grandes fotografías en la Jefatura del Servicio, su nombre estampado en letreros y su imagen transmitida por los recuerdos de sus antiguos discípulos. Es razonable, entonces, preguntarse ¿qué puede decir sobre él y su obra un médico de mi generación?

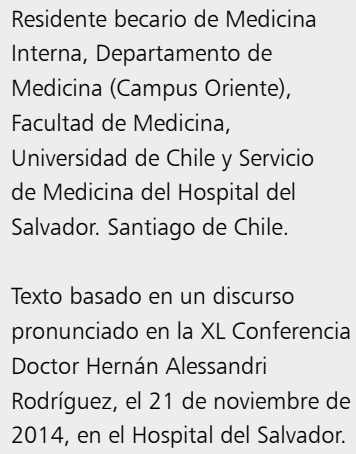

Texto basado en un discurso pronunciado en la XL Conferencia Doctor Hernán Alessandri Rodríguez, el 21 de noviembre de 2014, en el Hospital del Salvador. 
internacional, la manera de ver y hacer la medicina, la relación con el enfermo, con el "usuario", en los sesenta años que siguieron a la influencia del doctor Alessandri? ¿Se atreve alguien a proyectarse de aquí al año 2074?

Y entonces me pregunto: después de tantas décadas, ¿será el legado de don Hernán un caudal que alguna vez brotó en la cordillera y que hoy se agota en un desierto? ¿Qué significa para nuestra generación formarse como internistas en el "Servicio de Medicina Profesor Dr. Hernán Alessandri”, como reza una placa en un muro del edificio?

Reconozco que para sus discípulos su genio y figura despiertan aún esa ambivalencia afectiva que se tiene con un padre. Él pudo transformarse en el sustituto natural del primer objeto afectivo, el ser más fuerte, bondadoso y sabio de todos. El que enorgullece por sus virtudes, su sapiencia y justicia. Al que se ama entrañablemente por los más ínfimos motivos. Contra el que también se generan rebeliones potentes, pero que finalmente terminan en sometimiento completo ${ }^{1}$. Es un modelo del padre prístino que hoy, por su lejanía temporal, tal vez no inspira a los más jóvenes. Pero, reconocemos que de algún modo se replica y renace constantemente en las siguientes generaciones de docentes, con mayor o menor fuerza y pureza.

No puedo ni quiero rescatar el personalismo del doctor Alessandri, sino la idea detrás de su forma, lo trascendente. Quiero hablarles del modelo químicamente puro que puede aplicarse de aquí al fin de los tiempos. De ese imperativo ético, de ese manual deontológico que era el Profesor. Es decir, ¿qué valor tiene un profesor como el doctor Alessandri en el año 2014 y por qué será el mismo valor en el 2074?

El docente de hoy vive tiempos difíciles, dicen los entendidos ${ }^{2}$. Ha cambiado la imagen del profesor, ha cambiado la imagen del médico. A la ya compleja tarea de educar, al arte de tratar a un enfermo, se le han agregado factores como restricción de tiempo, exigencias familiares, barreras burocráticas que se hacen a veces infranqueables, interrupciones frecuentes, nulo reconocimiento del esfuerzo que todo esto implica. La respuesta tiende a ser la más sencilla: resignación y entrega "al sistema". Según estudios publicados, los dos estresores más relevantes para el docente son la estructura y cultura de la institución y la difícil interacción con el estudiantado.
La profesión más vieja del mundo compite en antigüedad con el arte de transmitir conocimientos. Desde un Hipócrates, Sócrates, Platón, Séneca, Cicerón, pasando por el clero medieval, la docencia recién se profesionalizó en Prusia en el siglo XVIII. Se profesionalizó como respuesta necesaria al progreso cada vez más veloz. Inicialmente se creó como una industria de producción en masa, con clases frontales que pretendían nivelar lo mejor posible a crecientes cantidades de alumnos. Los años dorados del docente los vivió -y sin duda contribuyó a que así fuera- el Profesor Alessandri. La autoridad y su dignidad venían implícitas en el cargo. Eso hoy ya no es así. A fines de la década de 1960 y a principio de los 70 (don Hernán se dio perfecta cuenta de ello) la polarización y politización de la sociedad llevaron al docente a la palestra como agente responsable del sistema imperante. Se buscaron alternativas, las críticas se hicieron abiertas, las exigencias aumentaron, los estudiantes se pusieron más difíciles y más numerosos. El perfil del docente se cargó de nuevos requisitos.

Desde entonces se exige de la imagen del profesor la "garantía explícita" de una docencia que debe transmitir contenido, educar, motivar, disciplinar, diferenciar identidades, hacer "coaching" de grupo y ser autoexigente. Un experto en docencia. Todo al mismo tiempo. El actuar docente se pone a prueba constantemente, no finaliza nunca.

Agreguemos a este caldo el fenómeno dinámico de la experiencia social de internet, los medios de información, los intercambios culturales y los cambios en la estructura familiar. Una competencia desleal para un docente de otra generación. Ahora no sólo los adolescentes son unos desadaptados.

Y, como si fuera poco, el docente ha perdido el estatus social del Maestro, del Profesor. Las cosas han cambiado mucho desde que "el prof pasara sus visitas a pacientes hospitalizados", en la sala Joel Rodríguez o en Máximo Hertel (que ahora es la sala de cuidados intermedios).

Pero, al final, si nos detenemos a mirar todo este enjambre con altura de miras, es posible darse cuenta que todo siempre vuelve a su origen: El ser y el deber ser. La esencia de la ética profesional docente. Ésta persevera, no cambia y ustedes podrán juzgar si el doctor Alessandri las tenía en consideración. Se pueden resumir en 5 ámbitos 
1. El ámbito de la profesión: niveles adecuados de competencia, perfeccionamiento continuo e investigación. En suma, capacidad para el desarrollo profesional autónomo. Pero todo eso con un fin particular: el beneficio del Hombre. Cito a Einstein: "Imponeos como interés la preocupación por el hombre mismo y su destino, solo así sus creaciones serán bendiciones para la humanidad". Sin duda que don Hernán tenía esto como premisa.

2. El ámbito de la institución: garantizar la tenencia de una política coordinada, curricular y disciplinaria, de la institución. Garantizar condiciones de trabajo adecuadas y servir de modelo de conducta. Supongo que no habrá dudas sobre la capacidad del doctor Alessandri para lograr esto.

3. El ámbito de la relación con los colegas: generar equipos de trabajo, respetar, colaborar. Obstáculos a esto serían la incomunicación, el malentendido orgullo profesional que hace ver amenazas en el otro y la capacidad de reconocer que hay un todo por encima de las especialidades. Vamos a ver quién opina que el Profesor no sabía de estas cosas.

4. La relación con los alumnos: el docente es un modelo, debe ser diligente en la promoción del alumno como ser humano, considerarlo agente y no paciente de su educación. Además, un docente deber ser veraz y aceptar que existen métodos para distinguir lo verdadero de lo falso. La verdad se encuentra, no se impone: debe evitar el dogmatismo. Recordar que el alumno no es un medio sino un fin. Esto quiere decir que el estudiante debe consolidar su autonomía intelectual. Todo esto requiere pruebas de humildad y he sabido que don Hernán podía emocionar haciendo gala de algo similar.

5. Finalmente, el ámbito de la sociedad: observar los deberes cívicos y los valores sociales. Hay una responsabilidad social en la formación de los profesionales.

En fin, creo que queda claro el punto. Esa es la sustancia que corría por las venas del doctor Alessandri como un don natural, que persiste pese a las revoluciones y los cambios. Esta sustancia es químicamente pura, imperativa y se resume en la deontología profesional. Esa sustancia hace a don Hernán un hombre universal porque, más allá de las virtudes y defectos personales, es el molde del que se forman los docentes.

Me atrevo a decir que muchos añoran con nostalgia una figura similar, contemporánea y consciente del espíritu de su tiempo, capaz de identificar los defectos y tener una visión, la templanza y el arrojo de trabajar en pos de soluciones. Tal vez el desarrollo de los eventos históricos no nos permita volver a gozar de la compañía de alguien que reúna todas esas características.

Pero, cuidado con eso. Yo creo que están ahí. Están en el alma de los docentes, grabadas y desarrolladas, en unos más, en otros menos. Están en el conjunto y están también en el inconsciente del alumno que es formado y que lo busca cuando pisa las baldosas de este hospital.

Tal vez ese modelo llamado Hernán Alessandri, ese río cordillerano torrentoso, ya no traiga mucho caudal aquí en este meridiano del tiempo aparentemente seco, pero desde lo profundo alimenta napas y de estas napas nacen y nacerán todavía tantos oasis color verde esperanza, color verde perseverancia.

\section{Referencias}

1. Freud S. Sobre la psicología del colegial. Sigmund Freud: Obras Completas. Editorial Biblioteca Nueva Madrid: 1948.

2. Gudjons H. Neue Unterrichtskultur-veränderte Lehrerrolle, Bad Heilbrunn. Klinkhardt: 2007.

3. Jover G. Ámbitos de la deontología profesional docente, Teoría de la Educación. Revista Interuniversitaria Vol. III. Salamanca. Ediciones Universidad: 1991 (Páginas 75-90).

Nota del Editor: El Dr. Sebastian Rosson Matzka nació en 1979 en Jena, Turingia, Alemania. Cursó su enseñanza media en el Instituto Nacional, Santiago de Chile (1995-1997) y en el Otto Schott Gymnasium, en Jena (1997-1999). Cursó estudios universitarios en la Friedrich Schiller Universität, en Jena (1999-2001) y en la Facultad de Medicina de la Pontificia Universidad Católica de Chile (2002-2008), donde se graduó Médico-Cirujano en enero de 2008. Actualmente cursa el tercer año de beca para Especialistas en Medicina Interna, en el Hospital del Salvador (2012-2014). 